\title{
REGULACIÓN JURÍDICA DEL TÉRMINO DEL EMPLEO A CONTRATA EN LA ADMINISTRACIÓN PÚBLICA
}

\author{
LEGAL REGULATION OF THE TRANSITORY EMPLOYMENT ENDING IN PUBLIC \\ ADMINISTRATION
}

Eduardo Castillo Vigouroux ${ }^{1}$

\begin{abstract}
Resumen:
Este artículo presenta la regulación jurídica del término del empleo a contrata en la Administración del Estado en Chile, las facultades de esta según nuestra legislación y su concordancia con las garantías constitucionales, principalmente del derecho a la igualdad, revisando la jurisprudencia administrativa y judicial sobre la materia.
\end{abstract}

Palabras clave: contrata - término anticipado - facultades de la Administración

\begin{abstract}
:
In this article the author analyzes the legal regulation of anticipated ending of transitory public employees in Chilean Public Administration, its legal faculties and its concordances with constitutional guarantees, principally with the right to be equally treated, checking administrative and judicial jurisprudence.
\end{abstract}

Key words: transitory employment - anticipated discharge - Administration faculties

1 Abogado. Licenciado en Ciencias Jurídicas, Universidad de Chile. Diplomado en Ciencia Política, Instituto de Estudios Políticos Universidad de Chile, Instituto de Estudios Aeroespaciales de la Fuerza Aérea de Chile, Universidad de La Frontera. Magíster en Derecho con mención en Derecho Constitucional, Universidad Católica de Temuco - Universidad de Génova, Italia. Correo: egcastill@uct.cl 
El régimen de las personas encargadas de ejercer la función pública ha variado sustancialmente en los últimos años. Este cambio se ha traducido, entre otros aspectos, en el reemplazo de un régimen que garantizaba la estabilidad en el empleo, en el cual el término del ejercicio de la función no queda a discreción de la autoridad, por un régimen de discrecionalidad de la autoridad para poner fin al empleo ${ }^{2}$.

Este cambio se ha ido operando paulatinamente a través de varios mecanismos. El más importante de ellos es la reducción de los cargos de planta frente al aumento sostenido de los cargos a contrata. Esto se ha logrado a través de:

a) La creación de servicios descentralizados, principalmente, con plantas exiguas que deben afrontar múltiples funciones.

b) La imposibilidad de reponer los cargos vacantes por jubilación o estímulos al retiro, norma establecida anualmente en las leyes de Presupuestos donde se permite reponer solo el $50 \%$ de dichas vacantes y siempre que el servicio respectivo cuente disponibilidad de fondos.

c) La eliminación del límite de las contratas establecido en el art. 10, inciso $2^{\circ}$, de la Ley $N^{\circ} 18.834$, Estatuto Administrativo.

d) La autorización legal a los funcionarios a contrata para ejercer jefaturas, cuestión reiteradamente negada por la jurisprudencia administrativa emanada de la Contraloría General de la República.

Estas tres últimas medidas se contemplan anualmente en la Ley de Presupuestos del Sector Público, la primera de ellas en las normas generales de la ley y la segunda en las glosas presupuestarias de cada servicio público. De allí la importancia progresiva del régimen del empleo a contrata ${ }^{3}$.

Los funcionarios a contrata se encuentran regidos por la Ley $\mathrm{N}^{\circ}$ 18.834, Estatuto Administrativo, cuyo texto refundido, coordinado y sistematizado fue fijado por el DFL 29 del año 2004, del Ministerio de Hacienda, publicado en el Diario Oficial del 16 de marzo de 2005.

2 Según el Estudio "Estadísticas de Recursos Humanos del Sector Público 2001 - 2010", publicado en octubre de 2011 por la Dirección de Presupuestos del Ministerio de Hacienda (DIPRES), el personal de planta de la administración central es de 85.547 funcionarios y el personal a contrata alcanza a 113.889 funcionarios. El estudio muestra el avance anual progresivo del empleo a contrata respecto a la provisión de los cargos de planta.

3 Ver la Ley $N^{\circ}$ 20.481, de Presupuestos del año 2011 en su artículo 10, y las glosas comunes a todos los Programas 01 de Funcionamiento de los Gobiernos Regionales; también pueden verse glosas de servicios como el FOSIS en la Partida 21 del Ministerio de Planificación, MIDEPLAN. 
Un régimen similar tienen los funcionarios municipales según la Ley $N^{0} 18.883$ que aprueba el Estatuto Administrativo para los Funcionarios Municipales ${ }^{4}$.

Para los efectos de este artículo tendré como referencia solamente la Ley $\mathrm{N}^{\circ}$ 18.834 sobre Estatuto Administrativo y, salvo referencia distinta, los artículos citados se refieren a dicha ley. Cabe señalar que el término de los empleos a contrata establecido en la Ley $\mathrm{N}^{\circ}$ 18.883, aplicable a los funcionarios municipales, es igual al regulado en la Ley $\mathrm{N}^{\circ} 18.834$.

La cuestión jurídica a plantearse es si este sistema permite afirmar que se cumple con lo dispuesto en el artículo 38 , inciso $1^{\circ}$, de la Constitución Política de la República, en lo relativo al régimen de carrera funcionaria fundada en principios de carácter técnico y profesional, y con la garantía constitucional contemplada en el $\mathrm{N}^{\circ}$ 17 del artículo 19 de la misma Carta, sobre la igual admisión a todos los empleos públicos sin otros requisitos que los que impongan la Constitución y las leyes.

Ese análisis lo haré respecto de uno de los temas más controvertidos en la regulación del empleo a contrata, que es el término anticipado del vínculo, decidido unilateralmente por la Administración. La pregunta que corresponde hacer es si la Administración puede poner término al nombramiento antes del plazo indicado en el nombramiento del funcionario. En otras palabras, si el funcionario fue nombrado hasta cierta fecha (por ejemplo, el 3 de julio, o el 31 de diciembre del año respectivo) puede ser despedido con anterioridad a esa fecha.

\section{I.- Las contratas en el régimen estatutario}

Para responder esa interrogante es necesario, previamente, hacer las siguientes consideraciones en torno a la naturaleza jurídica del empleo público y en particular de la contrata.

\section{1.- Naturaleza jurídica del vínculo entre la Administración y el funcionario público}

La doctrina y la jurisprudencia administrativa han señalado que la naturaleza jurídica de la relación entre el funcionario y la Administración tiene el carácter de un vínculo estatutario de derecho público. Así lo señaló la Contraloría en el Dictamen

4 La ley $N^{\circ} 18.883$ Estatuto Administrativo para Funcionarios Municipales, en su artículo $2^{\circ}$, inciso $4^{\circ}$, señala que el gasto de los empleos a contrata no pueden superar el veinte por ciento del gasto de remuneraciones de la planta municipal, disposición que es respetada por las Municipalidades. 
31000N08 al informar al Tribunal Constitucional en el recurso de inaplicabilidad por inconstitucionalidad Rol Nº 1133-2008 INA.

"No obstante ello, conviene tener presente que la jurisprudencia administrativa ha reconocido que el vínculo que une a los servidores públicos con la Administración y que se conoce como vínculo estatutario" en su sentido amplio, supone la sujeción de los funcionarios, empleados o servidores públicos a un régimen de derecho público preestablecido, unilateral, objetivo e impersonal, fijado por el Estado, cualquiera sea el nombre específico que pudieran recibir los diversos cuerpos estatutarios que los rijan y sea cual fuere la naturaleza del servicio en que se desempeñen. (Estatuto Administrativo Interpretado, Coordinado y Comentado, Ley 18.834, Jurisprudencia Administrativa, Contraloría General de la República, 75 años de Vida Institucional, Santiago de Chile, 2002, p. 17; dictámenes $\mathrm{N}^{\circ}$ s. 27.438, de 1957 y 31.386 , de 1982)".

Esto significa que el vínculo se encuentra establecido con anterioridad al nombramiento del funcionario, que le es obligatorio respetarlo, y por ello el vínculo se inicia con un acto unilateral de la Administración, denominado nombramiento, y no con un acto bilateral como lo es el contrato.

\section{2.- Naturaleza jurídica de la contrata}

La contrata participa plenamente de la naturaleza jurídica del vínculo estatutario y de los efectos de aquel. Sin embargo, es necesario hacer algunas precisiones para resolver la cuestión planteada.

\section{1.- La contrata participa de la misma finalidad que el cargo de planta}

El artículo $2^{\circ}$ señala que los cargos de planta y a contrata solo "podrán corresponder a funciones propias que deban realizar las instituciones" a que se refiere el artículo $1^{\circ}$ del mismo Estatuto. Esto las distingue de los honorarios.

En el régimen estatutario se contempla que las actividades que no corresponden a funciones propias se efectúen por el sector privado, entre ellos personas naturales contratadas a honorarios.

Las funciones propias están en la ley orgánica de cada servicio y en el marco regulatorio de la Administración del Estado, como lo son la Ley Orgánica Constitucional de Bases, la Ley de Presupuestos, la Ley de Acceso a la Información Pública, el Estatuto Administrativo, etc. 


\section{2.- El empleo a contrata, al igual que el cargo de planta, es un cargo público a través del cual se realiza la función administrativa.}

Por tal razón e rigen todas las normas estatutarias correspondientes, como por ejemplo el Estatuto Administrativo que contempla obligaciones y derechos funcionarios, calificaciones, prohibiciones e incompatibilidades, responsabilidad administrativa y su extinción, cesación de funciones.

\section{3.- El empleo a contrata es transitorio}

Según el art. 10 duran como máximo hasta el 31 de diciembre de cada año. Esta duración máxima es un límite que concuerda con la disponibilidad de fondos establecida anualmente en la Ley de Presupuestos del Sector Público.

2.3.1.- Si el plazo es hasta el 31 de diciembre el nombramiento expira por el solo ministerio de la ley, según el artículo 10 , inc. $1^{\circ}$, salvo que se hubiere dispuesto la prórroga y tal situación se haya notificado previamente por escrito al funcionario.

2.3.2.- El plazo de la contrata puede tener fecha de término anterior al 31 de diciembre del año correspondiente. En la Resolución $N^{0}$ 1.600/2008, art. 7.1.1.- , letra c), la Contraloría exime del trámite de toma de razón los nombramientos de contratas por un plazo inferior a 15 días. En tal caso la jurisprudencia ha aplicado el mismo criterio señalado en el número anterior, es decir, llegado el plazo el nombramiento expira por el solo ministerio de la ley.

2.3.3.- Podemos señalar que en ambos casos opera la misma causal de terminación o cesación de la función pública debido al término del período legal por el cual se es designado. Esta causal es exclusiva para las contratas y no rige para los funcionarios de planta. A contrario, las causales de cesación de los cargos de planta también se aplican a los contratas (renuncia, jubilación, destitución, fallecimiento).

Sin embargo, todos los funcionarios públicos (plantas y contratas) tienen derecho a la función que consiste en que no pueden ser separados de sus empleos sino por una causa legal de expiración de funciones contempladas en el Estatuto Administrativo. Debemos tener cuidado en no confundir este principio con el derecho a la estabilidad en el empleo del que gozan solo los plantas por ser un principio de la carrera funcionaria ${ }^{5}$.

5 La Contraloría General de la República en Dictámenes relativos al art. 231 del DFL 338/1960, anterior Estatuto Administrativo, señaló que "La expiración de funciones del personal contratado solo procede por alguna de las causales indicadas en el Estatuto Administrativo y no anticipadamente". (22.859/65 y $32.341 / 65)$. 
2.3.4.- La ley admite la prórroga de las contratas mediante decreto o resolución no afecta al trámite de toma de razón según el Artículo $7^{\circ}, 7.1 .1 .-$, letra d), de la Resolución No 1.600/2008 de la Contraloría. Es evidente que si la autoridad o jefe del servicio ha dispuesto la prórroga es porque la función que realiza "el contratado" es necesaria y la ha realizado bien, de lo contrario no renovaría su nombramiento. Si la autoridad nada dice se entiende que el nombramiento expira el día señalado como plazo de término.

2.3.5.- Los funcionarios a contratas no pueden ejercer jefaturas. Ello porque se trata de un empleo transitorio que no se condice con labores de dirección. La Contraloría General de la República ha señalado que ello solo se permite si una ley lo autoriza. En la práctica esas excepciones legales están consagradas anualmente en las Leyes de Presupuestos respecto de cargos específicos de algunos servicios que no tienen suficientes funcionarios de planta para cubrirlos.

2.3.6.- Por su transitoriedad a las contratas no se les extiende el régimen de la carrera funcionaria tal como se señala en los artículos 44 a 51 de la Ley $\mathrm{N}^{\circ}$ 18.575, Orgánica Constitucional de Bases Generales de la Administración del Estado.

En la realidad las contratas no son cargos excepcionales porque constituyen la mayoría del empleo público en los servicios centralizados y descentralizados, salvo en las Municipalidades; el vínculo entre el funcionario y la Administración generalmente es estable porque se prolonga por años (hay casos de más de 20 años de un funcionario a contrata); y, como ya se dijo, ejercen jefaturas autorizados por la ley. 


\section{El término de las contratas}

Volviendo al tema central que nos ocupa analizaré el término anticipado del empleo a contrata por decisión unilateral de la Administración en relación al cumplimiento de la normativa constitucional y legal sobre la materia.

El término anticipado de la contrata antes de la llegada del plazo señalado en el nombramiento respectivo se ha dado en dos situaciones distintas según sea el contenido de la resolución de nombramiento.

La primera fórmula es aquella en que la resolución de nombramiento solamente señala el día hasta el cual dura el nombramiento sin agregar otras frases alternativas.

Pero el caso más generalizado es aquel en el cual la resolución señala el plazo de término del nombramiento (por ejemplo, "hasta el 30 de junio de 2011" o "hasta el 31 de diciembre de 2010") a lo que se agrega una frase como la siguiente "o hasta que sus servicios sean necesarios" u otra de similar contenido.

Como en ambos casos la situación es distinta, se analizarán por separado.

\section{3.- El término de las contratas antes del vencimiento del plazo}

3.1.- Concentrémonos en el término anticipado de la contrata antes del vencimiento del plazo sin que se contemple la frase "o hasta que sus servicios sean necesarios". En tal caso debemos recurrir a las causales de término propios de la respectiva contrata que es la llegada del día previsto para su término, cualquiera haya sido el plazo fijado en el nombramiento. La pregunta primera es si la autoridad tiene facultades para poner término anticipadamente a una contrata, es decir, antes de la llegada del plazo.

El Dictamen Nº 39.562 de 2005 de la Contraloría señaló que

"los funcionarios contratados gozan del derecho a la estabilidad en el empleo, pero con las limitaciones propias que emanan del carácter transitorio de sus designaciones, de manera que la seguridad en sus cargos que les garantiza la ley estatutaria dice relación con la circunstancia de que su expiración de funciones solo procede por alguna de las causales legales que ella consulta, a menos que el contrato haya sido dispuesto bajo la fórmula "mientras sean necesarios sus servicios"..." (Este Dictamen fue citado por el CDE en el Recurso de Protección Rol No 1466-2010, C. de A. de Temuco). 
De tal forma la Contraloría reconoce el derecho de propiedad sobre la estabilidad en el empleo pero no el derecho de propiedad sobre el cargo que contempla el artículo $4^{\circ}$, inciso $2^{\circ}$, de Estatuto Administrativo.

De la misma manera razona la C. de A. de Temuco en el fallo del recurso de protección Rol No 1466-2010, al señalar que

"De la simple lectura de la resolución $n^{\circ} 128$, resulta que el recurrido no tiene la facultad de poner término anticipado a las funciones que desempeñan los recurrentes, y en consecuencia, debe respetar el plazo que fija la misma resolución". La Resolución No 128 es la que nombra a contrata a los dos recurrentes hasta el 31 de diciembre de 2010.

Este fallo de la Corte de Apelaciones de Temuco señala como vulneradas las garantías constitucionales del artículo $19, \mathrm{~N}^{\circ}$ s. 24 y 2, y es interesante porque está referido a un caso en que la resolución de nombramiento de la contrata no contiene la frase "o hasta que sus servicios sean necesarios".

3.3.- El criterio anterior fue desechado por la Corte Suprema en el fallo del citado recurso de protección que llegó a su conocimiento por la vía de la apelación (Rol de Ingreso 200-2011). En efecto, la Tercera Sala de la Corte Suprema al revocar el fallo de la C. de A. de Temuco, hace varias consideraciones que paso a exponer.

3.3.1.- La primera consideración es que en la Resolución № 128, de nombramiento de la contrata, se señala que "por razones de buen servicio, se hace necesario contratar a las personas que se indican...", es decir, el fundamento de la contrata fue "razones de buen servicio que las hacían necesarias".

3.3.2.- Lo anterior está en armonía con la naturaleza transitoria de la contrata y que no pueden durar más allá del 31 de diciembre de cada año, expirando en sus funciones por el solo ministerio de la ley. Sostiene el fallo que de allí se desprende que "figura implícita la facultad de la autoridad para poner término a las funciones del empleado a contrata antes de la fecha recién indicada".

3.3.3.- En vista de lo anterior la frase del Considerando de la Resolución "por razones de buen servicio, se hace necesario contratar a las personas que se indican...", ha sido empleada "para permitir en esta clase de nombramientos la existencia de un período de vigencia que sea inferior al que le restare al empleo para finalizar el año en que los servicios recaigan". Por ello la autoridad se encuentra facultada para cesar los servicios pues estos tienen como principal característica "la precariedad en su duración, supeditada a las necesidades de la entidad empleadora". Finaliza el fallo de la Corte señalando que "En esas condiciones, no era menester una mayor fundamentación". 
3.3.4.- No podemos menos que disentir de tal pronunciamiento por las razones siguientes:

- Que la autoridad administrativa consigne en un considerando de la resolución de nombramiento que "se hace necesario contratar a las personas..." constituye un fundamento de su resolución, a lo cual está obligada en virtud del artículo $8^{\circ}$ de la Constitución, del artículo 13 , inciso $2^{\circ}$, de la Ley $N^{\circ} 18.575$, artículos 16 y 41, inciso $4^{\circ}$, de la ley $N^{\circ} 19.880$, y Resolución N ${ }^{\circ} 1.600$ de la Contraloría General de la República. Dado el número de empleos a contrata y la diversidad de funciones (profesionales, técnicos, administrativos, auxiliares de diversos programas de MIDEPLAN) contemplados en la Resolución No 128 es obvio que el fundamento se haga en términos genéricos y no específico para cada uno de los 189 funcionarios nombrados por la citada resolución.

- La argumentación que de la naturaleza transitoria de la contrata se desprenda que la autoridad tiene facultades implícitas para ponerle término antes de la fecha de término contraviene el artículo $7^{\circ}$ de la Constitución en la parte que dispone que la autoridad no tendrá otras facultades que las que expresamente le señale la ley. La Corte Suprema, en el ejercicio de interpretación de una resolución administrativa, otorga a la autoridad facultades implícitas y no es que desde una ley desprenda tal clase de facultades, que podrían ser parte de otras más genéricas, sino que crea nuevas facultades a partir del texto de una resolución, lo que no solo constituye una vulneración del principio de legalidad sino que además abre las puertas a la arbitrariedad en la afectación de los derechos garantizados por la Constitución.

- El fallo de la Corte Suprema da, equivocadamente, un sentido a esa frase y señala que la autoridad la consignó precisamente para permitir su término antes del 31 de diciembre de 2010, en sus palabras "para permitir en esta clase de nombramientos la existencia de un período de vigencia que sea inferior al que le restare al empleo para finalizar el año en que los servicios recaigan". En mi parecer la autoridad que hizo el nombramiento tuvo la intención precisamente contraria que fue asegurar que las contratas se prolongaran hasta el 31 de diciembre a fin de no afectar las labores permanentes y los programas de MIDEPLAN. Cualquier análisis mínimo de los hechos así lo revela pues no se incluyó en el texto de la parte resolutiva del acto administrativo la frase "o hasta que sus servicios sean necesarios" y la lógica de la no inclusión de aquella obedece al sentido que le dio el Dictamen No 39.562 del año 2005, ya citado en el punto 3,1 .

- Señalar que el empleo a contrata tiene un carácter de "precario", como lo hace el fallo de la Corte Suprema, es confundir los conceptos de precariedad y transitoriedad. Efectivamente el nombramiento a contrata es transitorio pero no precario, es decir, la autoridad no puede ponerle término a su arbitrio antes del 
vencimiento del plazo; sí puede ponerle fin por razones fundamentadas en el buen servicio. Tal finalidad es reconocida por el Dictamen N N 39.562 de 2005 de la Contraloría, ya mencionado.

- Por último el fallo de la Corte Suprema también yerra al afirmar que en el caso presentado "no era menester una mayor fundamentación" porque contradice todo el avance que ha tenido el Derecho Administrativo chileno a partir de la modificación a la Ley $N^{\circ} 18.575$ con la dictación de la Ley $N^{\circ} 19.653$, conocida como Ley de Probidad, con la reforma constitucional al artículo $8^{\circ}$ el año 2005, con la dictación de la Ley $N^{\circ} 20.285$ sobre Transparencia y con los estándares fijados por la Contraloría General de la República en la Resolución № 1.600 sobre toma de razón.

4. La duración del empleo a contrata y la expresión "hasta que sus servicios sean necesarios" o "hasta que sean necesarios sus servicios"

\section{1.- Algunas constataciones}

Los nombramientos a contrata se hacen hasta una fecha determinada, muchas veces hasta el 31 de diciembre del respectivo año aunque no es raro encontrar otros plazos más breves, de meses. No cabe duda el carácter eminentemente transitorio del empleo a contrata.

En muchos nombramientos a contrata se incluye una frase como la siguiente. "La contrata durará hasta el 31 de diciembre de 2008, o hasta que sean necesarios sus servicios".

La Contraloría ha reconocido esta cláusula aun en los casos en que no está escrita. Por ejemplo, en el Oficio Ord. No 04167, del 20 de julio de 2010, dirigido a MIDEPLAN, sostiene que la Resolución N $N^{\circ} 128$ tiene el carácter de prórroga de los nombramientos de los años anteriores por lo que "tales designaciones se adoptaron en las mismas condiciones fijadas en la contratación primitiva, y en sus pertinentes prórrogas." Este pronunciamiento fue solicitado por MIDEPLAN mediante Oficio Ord. 40-1408/2010 del 10 de junio de 2010 y contradice la jurisprudencia anterior contenida en los Dictámenes 39.562 de 2005 y, anteriormente en el Dictamen 32.341 del año 1965.

4.2.- Los temas a dilucidar en estos casos es si la frase "o hasta que sus servicios sean necesarios" es indicativa de modificación del plazo, si en tal caso la autoridad puede poner término a la contrata a su arbitrio y sin fundamento y si la autoridad tiene límites al dictar la resolución de término de la contrata. 
4.2.1.- La Contraloría en Dictámenes 16.557, 26.594, 52.928 y 54.598, todos de 2010, ha declarado que "cuando una contratación ha sido dispuesta con la fórmula "mientras sean necesarios sus servicios" u otra similar, la autoridad puede ponerle término en el momento que estime conveniente...". (Dictamen 54.598).

En otras palabras, para la Contraloría la frase "mientras sean necesarios sus servicios" no dice relación con el fundamento del término de la contrata sino que con el plazo, habilitando a la autoridad para poner término a la contrata antes del vencimiento del plazo fijado en el nombramiento respectivo.

En el mismo sentido se pronuncia la Corte Suprema que ha señalado que cuando el nombramiento contiene la frase "mientras sean necesarios sus servicios" "figura implícita la facultad de la autoridad para poner término a las funciones del empleado a contrata antes de la fecha indicada". (Considerando $4^{\circ}$ del faIlo recaído en la causa $\mathrm{Rol} \mathrm{N}^{\circ}$ 7981-2010). Igual argumento se encuentra en el considerando $7^{\circ}$ del fallo recaído en la causa Rol No 200-2011 (1466-2010 de la C. de A. de Temuco) y en el Considerando $7^{\circ}$ del fallo recaído en causa Rol $N^{\circ}$ 1475-2011. En los tres casos se trata de apelaciones de recurso de protección previamente acogidos por las Cortes de Apelaciones.

Las causales de término están expresamente señaladas en el Estatuto Administrativo, en su artículo 146 y no hay otras. Es más, el artículo 153 del mismo Estatuto complementa la disposición del artículo 146, letra f). En ninguna parte aparece como causal de término de la función pública la decisión de la autoridad fundada en no ser necesarios los servicios de alguien que desempeña la función pública y quien dicta un acto administrativo de esa naturaleza infringe el principio de legalidad En definitiva, se aplica una causal de término de la función pública no prevista en la ley.

4.2.2.- Las resoluciones que ponen término a las contratas anticipadamente no contienen fundamento alguno para ello sino que hacen mención a que los servicios ya no son necesarios.

La Corte Suprema en fallos recaídos en las causas Rol No 7981-2010, 200-2011 y 1475-2011 ha sostenido que autoridad está facultada para cesar las contratas bastando para ello la alusión genérica de la no necesariedad de los servicios.

Como se aprecia la Corte Suprema no se pronuncia directamente sobre la necesidad de fundamentar las decisiones de la autoridad.

Y esto es importante para aquilatar la racionalidad o ausencia de arbitrariedad de la decisión de la autoridad. Además de respetar la forma de poner fin a una contrata la autoridad no debe actuar arbitrariamente. Para ello nuestro ordenamiento constitucional consagra el principio de la transparencia de los actos de 
los órganos del Estado y elemento constitutivo esencial de esa transparencia es el fundamento de los actos porque solo así se puede determinar si un acto es o no arbitrario o excede las potestades de quien lo ejecuta. La justicia y rectitud del acto administrativo está asegurada por la publicidad de sus fundamentos de acuerdo con el artículo $8^{\circ}$ de la Constitución Política. Ello es reafirmado por la Resolución N 1.600 de la Contraloría General de la República, en su artículo 6.

En resumen, sin fundamentos no hay garantía de transparencia ni de publicidad afectándose el ejercicio del derecho a la igualdad.

4.2.3.- Límites de la autoridad para poner término anticipado a una contrata. Ya señalamos que en los Dictámenes de Contraloría y en los fallos de la Corte Suprema no parecen existir límites al actuar de la autoridad cuando pone término a una contrata en forma anticipada.

Los límites del actuar administrativo están determinados por las disposiciones legales preestablecidas y esa subordinación a la ley no es solo considerando su tenor literal sino también su espíritu. Es decir, el ejercicio de las potestades administrativas exige que la autoridad se subordine a la ley; ello sucede, por ejemplo, cuando adopta una decisión a través de un acto administrativo. Los artículos 6 y 7 de la Constitución son enteramente aplicables a estas decisiones de la autoridad de poner término al empleo de un funcionario público.

La conciliación entre el principio de legalidad y la discrecionalidad, es decir, ausencia de toda arbitrariedad, es un asunto que los jueces deben apreciar cuando ejercen la labor de control del acto de la administración a través del recurso de protección principalmente. 


\section{Conclusiones}

El término de una contrata antes del vencimiento del plazo contemplado en el decreto o resolución como fecha de término es ilegal porque vulnera derechos consagrados constitucionalmente, como el derecho de propiedad, no en el sentido de propiedad del cargo, sino que propiedad sobre la estabilidad en el empleo hasta la fecha contemplada en el nombramiento (art. $19 \mathrm{~N}^{\circ} 24$ de la Ct.), y el derecho a la igualdad pues se pone término a una o más contratas sin contener consideración alguna que explique por qué se las distingue de las otras que permanecen en el servicio. Tampoco se trata que las labores permanentes del servicio que ellos ejecutaban ya no se realizarán; por el contrario, esas funciones seguirán desarrollándose por otras personas pues el servicio no puede dejar de cumplirlas.

En cuanto al derecho de propiedad es necesario aclarar que se trata de "un derecho a permanecer en sus cargos mientras no opere alguna de las causales de expiración de funciones, salvo cuando su designación haya sido dispuesta bajo la señalada expresión u otra similar...", refiriéndose a la expresión "o hasta cuando sus servicios sean necesarios", en el caso que se contemple esa frase (Dictamen $N^{\circ} 54.354$ del 14.9.2010), caso que ya vimos.

En cuanto al derecho a la igualdad, es pertinente citar los fallos del Tribunal Constitucional que se refieren al derecho a la igualdad. Entre ellas las Rol No 53 1988 y $219-1995$. El primer fallo señala:

"De esta manera la igualdad ante la ley consiste en que las normas jurídicas deben ser iguales para todas las personas que se encuentren en las mismas circunstancias $y$, consecuencialmente, diversas para aquellas que se encuentren en situaciones diferentes. "No se trata, por consiguiente, de una igualdad absoluta sino que ha de aplicarse la ley en cada caso conforme a la diferencias constitutivas del mismo. La igualdad supone, por lo tanto, la distinción razonable entre quienes no se encuentren en la misma condición..." (Linares Quintana, Segundo, Tratado de la Ciencia del Derecho Constitucional Argentino y Comparado, tomo $4^{\circ}$, pág. 263)."

A su vez el fallo dictado en la causa Rol N²19-1995, en su considerando 17 cita textualmente el fallo anterior y agrega lo siguiente:

"Es decir, la igualdad ante la ley presupone que se trate en forma igual a quienes son efectivamente iguales, y solo a ellos, y en forma desigual a quienes no lo sean. Ahora, si se hacen diferencias, pues la igualdad no es absoluta, es necesario que ellas no sean arbitrarias, y es por ello que este Tribunal en la misma sentencia hizo suyas otras expresiones del mismo tratadista Linares Quintana sobre este punto, señalando que: "la razonabilidad es el cartabón o standard de acuerdo con el cual debe apreciarse la medida de igualdad o la desigualdad". 
Como vemos, para explicar o justificar el término anticipado de una contrata se exige una "razonabilidad" que solo puede expresarse a través de la fundamentación de la decisión de la autoridad de poner anticipadamente término a una contrata.

Hay, sin embargo otras dos disposiciones constitucionales atingentes a la materia que nos ocupa. El artículo 38, inciso $2^{\circ}$ de la Constitución, señala que una ley orgánica constitucional "asegurará" la igualdad de oportunidades de ingreso a la Administración del Estado. A su vez, el artículo 19 № 17 de la Constitución asegura a todas las personas "la admisión a todas las funciones y empleos públicos, sin otros requisitos que los que impongan la Constitución y las leyes".

Estas dos disposiciones tienen un común denominador que es garantizar una igualdad en el ingreso a la Administración del Estado. Siguiendo la tesis sustentada por el Tribunal Constitucional en la causa Rol N²26-1995 podemos decir que el derecho de igual admisión a los empleos públicos lleva implícito otro derecho que es el de la igualdad a permanecer en el empleo público. En efecto, al garantizarse la igualdad en el ingreso a todos los empleos públicos -y aquí el artículo $19 \mathrm{~N}^{\circ} 17$ de la Constitución no hace distingos entre plantas y contratas- también se está garantizando la igualdad a permanecer en el empleo público; el Estatuto Administrativo aplica este principio constitucional al señalar en forma expresa las causales de término de una contrata. La igualdad en el ingreso no tendría sentido sin la igualdad en la permanencia en el empleo porque el primero podría ser vulnerado a través de la vulneración del segundo.

Las diferencias que se pueden dar en ambos casos, ingreso y término, están determinadas por la ley, en un caso señalando los requisitos de ingreso y en el otro señalando expresamente las causales de cesación de servicios. Y entre estas últimas no aparece la de poner término anticipado a una contrata antes del vencimiento del plazo ni se exime a la autoridad de la obligación de fundamentar su decisión porque solo de ese modo podrá dar garantías, y los ciudadanos tener esa seguridad, de respeto del derecho a ser tratado de igual forma que los demás que están en su misma situación.

En todo caso, la jurisprudencia de nuestros Tribunales, especialmente de las Cortes de Apelaciones en los fallos de recursos de protección, ha ido evolucionando positivamente en el sentido de garantizar estos derechos y la Corte Suprema ya dictó un fallo favorable en la apelación Rol № 884-2011, acogiendo el recurso de protección porque la autoridad no puede asilarse en las "necesidades del servicio" toda vez que dicha causal no ha sido contemplada en el nombramiento por lo que la autoridad no tiene facultad para poner fin a las funciones de la recurrente. Este fallo fue dictado el 1 de marzo de 2011 por la Sala de Verano de la Corte Suprema. 
Finalmente, una reflexión en torno a lo planteado en el comienzo de este artículo. Con la amplitud que tiene el régimen del empleo a contrata en la Administración Pública chilena, y con mayor razón si se extiende cada vez más, es indispensable regularlo de una forma integral y, específicamente, otorgar a esos servidores públicos la seguridad que el término de sus servicios se regirá estrictamente por las causales establecidas en la ley y que la autoridad no podrá actuar arbitrariamente. 
